\title{
Malignant Gastric Outlet Obstructions: Treatment with Self-Expandable Metallic Stents
}

\author{
Jin Hyoung Kim, Ho-Young Song, and Ji Hoon Shin \\ Department of Radiology and Research Institute of Radiology, Asan Medical Center, University of Ulsan College of Medicine, Seoul, Korea
}

Unresectable malignant gastric outlet obstruction (GOO) severely affects the quality of life, with complications that include nausea, vomiting, aspiration, pain, and malnutrition. Although palliative surgical procedures have been traditionally performed, they are associated with high morbidity and mortality rates. Placing self-expandable metallic stents is associated with higher clinical success rates, lower morbidity, shorter time from the procedure to starting oral intake, lower incidence of delayed gastric emptying, and a shorter hospital stay than palliative surgery. Fluoroscopic or endoscopic placement of either bare or covered selfexpandable metallic stents is a safe, nonsurgical, palliative treatment option for unresectable malignant GOOs, with a high clinical success rate and a low rate of serious complications. Stent obstruction and migration are the most common complications, but most can be managed by interventional treatments. Although there have been substantial developments in stent design over the past decade, large prospective, randomized studies are required to determine the ideal stent for malignant GOOs. (Gut Liver 2010; 4(Suppl. 1):S32-38)

Key Words: Malignant gastric outlet obstruction; Palliative treatment; Placement of a self-expandable metallic stent; Endoscopy; Fluoroscopy

\section{INTRODUCTION}

Unresectable malignant gastric outlet obstructions (GOO), most commonly caused by gastric or pancreatic cancer, have a major negative impact on patient quality of life, with complications that include nausea, vomiting, aspiration, pain, and malnutrition. ${ }^{1-3}$ The primary goal of treatment in these patients is palliation of obstructive symptoms, thereby improving quality of life. ${ }^{4}$ Although palliative surgical procedures have been traditionally performed, they are associated with high rates of morbidity and mortality, due to advanced disease and poor general condition. $^{1,2,5}$

More recently, fluoroscopically- or endoscopically-guided placement of either bare or covered self-expandable metallic stents has been increasingly used as a safe, nonsurgical, palliative treatment option for patients with unresectable malignant GOOs. ${ }^{1-12}$ Placement of self expandable metallic stents is associated with higher clinical success rates, less morbidity, shorter times from the procedure to starting oral intake, lower rates of delayed gastric emptying, and shorter hospital stay than palliative surgery. ${ }^{13,14}$ This article reviews the use of this minimally-invasive therapeutic option in the palliative treatment of unresectable malignant GOOs.

\section{STENT TYPES}

Over the past decade, there have been substantial developments in stent design. Metallic stents may be largely divided into two groups, bare and covered metallic stents, depending on the presence of a covering membrane, with each having advantages and disadvantages. Bare stents are associated with lower migration rates because they embed themselves into the tumor and surrounding tissue and are incorporated into the wall of the organ. ${ }^{12}$ In addition, bare stents require smaller introducing systems than covered stents. However, bare metallic stents are susceptible to tumor ingrowth, which may lead to early recurrence of obstructions. Although recurrent obstructions caused by

\footnotetext{
Correspondence to: Ho-Young Song

Department of Radiology and Research Institute of Radiology, Asan Medical Center, University of Ulsan College of Medicine, 86 Asanbyeongwon-gil, Songpa-gu, Seoul 138-736, Korea

Tel: +82-2-3010-4370, Fax: +82-2-476-0090, E-mail: hysong@amc.seoul.kr DOI: $10.5009 / \mathrm{gnl} .2010 .4 . \mathrm{S} 1 . \mathrm{S} 32$
} 
tumor ingrowth have been reduced through use of covered metallic stents, ${ }^{15,16}$ covered stents are associated with higher migration rates because they are insufficiently anchored to the tumor and/or intestinal wall. ${ }^{17}$ Furthermore, there are high risks of biliary obstruction when covered stents are placed across the ampulla of Vater. The recent introduction of dual-design stents, composed of an outer, partially covered stent and an inner bare stent or an outer bare stent and an inner, fully covered stent, has resulted in low rates of stent migration and resistance to tumor ingrowth. ${ }^{2,6,12,18}$ Other authors have introduced a new duodenal bare metallic stent, through which biliary stenting is safe and effective, for the palliative treatment of malignant biliary and duodenal obstruction. $^{19}$

Different types of covering materials have been utilized to cover expandable metallic stents, including polyurethane, silicone rubber, and nylon., ${ }^{2,6,16,20,21}$ Disruption of the covering membrane may lead to tumor ingrowth, ${ }^{20}$ with polyurethane membranes in the gastroduodenal area being particularly susceptible to chemical degradation after exposure to acidic gastric fluid, bile salts, and certain hydrolytic enzymes in pancreatic secretions. ${ }^{22}$

\section{STENT PLACEMENT PROCEDURE}

Several days before stent placement, computed tomography, endoscopy, or barium series is performed to evaluate the site, severity, and length of the stricture. A nasogastric tube is inserted at least 24 hours before the procedure to ensure adequate gastric emptying. An empty stomach becomes cylindrical and permits easier catheter manipulation and advancement of the stent delivery device.

The procedure is performed under conscious sedation and analgesia (e.g., intravenous midazolam and fentan$y l) .^{23,24}$ The pharynx is anesthetized with $1 \%$ lidocaine spray. Stents may be inserted endoscopically with fluoroscopic assistance by gastroenterologists or via fluoroscopy alone by interventional radiologists. Patients are placed in the right lateral decubitus position, and the stricture is initially traversed using a guidewire. Under a combination of endoscopic and fluoroscopic guidance, the stent delivery system is advanced through the working channel of the endoscope over a stiff guidewire, positioned across the stricture, and deployed. Alternatively, under fluoroscopic guidance only, a guidewire and catheter $(100 \mathrm{~cm}, 5$ or $6 \mathrm{Fr}$ ) are inserted through the mouth across the stricture into the distal portion of the stomach or duodenum. Looping of the catheter-guidewire system can be reduced by using a 12 Fr or 18 Fr guiding sheath. ${ }^{25}$ Once the catheter has passed beyond the stricture, water-soluble contrast medium is injected to delineate the stricture. The stent delivery system is then advanced over a stiff guidewire and the stent is deployed under fluoroscopic guidance.

Very tight stenoses may be predilated with a $10 \mathrm{~mm}$ balloon to allow easier passage of the stent delivery system. ${ }^{6,12,26}$ The stent should be $2-4 \mathrm{~cm}$ longer than the stricture to reduce the risk of tumor overgrowth. ${ }^{3,27}$ In patients with technical failure to negotiate the guide wire though the stricture under fluoroscopic guidance, the guide wire may be negotiated through the stricture under combined endoscopic and fluoroscopic guidance at the same sitting. In patients with strictures longer than 10 $\mathrm{cm}$, two or three stents may be placed in a stent-within-stent fashion to achieve complete coverage of the stricture. ${ }^{6}$ Once the stent is sited, balloon dilation is usually not required, as most self-expanding stents will gradually expand and reach their full diameter. However, stents that expand less than half of the diameter of the stricture may be dilated. ${ }^{6,12}$

Patients are advised to resume oral intake of liquids within 24 hours after stent placement and to advance to a normal diet as soon as they can tolerate one. ${ }^{12}$ Patients are subjected to a barium study one day after stent placement to verify the position and patency of the stent. Patients are not allowed a soft or solid diet until follow-up shows full stent expansion. ${ }^{12}$ Patients are advised to chew their food well and to avoid high-fiber foods in order to reduce the risk of food bolus obstruction. ${ }^{27}$

\section{TECHNICAL AND CLINICAL SUCCESS}

Technical success is defined as successful placement and deployment of the stent across the stricture. ${ }^{28}$ Clinical success is defined as the relief of symptoms and/or the improvement of oral intake, ${ }^{28}$ obviating the need for palliative surgery. ${ }^{15}$ A systematic review of 32 publications $^{28}$ describing a total of 606 patients with malignant GOO who underwent metallic stenting under fluoroscopic or endoscopic guidance, found that the technical and clinical success rates were $97 \%$ and $89 \%$, respectively. Results of large or multicenter studies have shown similar success rates for endoscopic and fluoroscopic stent placement (Table 1). ${ }^{1,6,7,29,30}$

Complicated anatomy, severe stenosis, or acute angulation of a bowel loop may result in technical failure. ${ }^{27}$ Technical success rates are dependent on the site of lesion. ${ }^{6}$ For example, stent placement at the site of a duodenal obstruction is technically more difficult than in the peripyloric region, not only because of loop formation of 
Table 1. Expandable Metallic Stents in Malignant Gastric Outlet Obstruction

\begin{tabular}{|c|c|c|c|c|c|c|}
\hline \multirow{2}{*}{ Reference } & \multirow{2}{*}{$\begin{array}{l}\text { No. of } \\
\text { patients }\end{array}$} & \multirow{2}{*}{ Guidance } & \multirow{2}{*}{$\begin{array}{c}\text { Technical } \\
\text { success rate }(\%)\end{array}$} & \multirow{2}{*}{$\begin{array}{c}\text { Clinical success } \\
\text { rate }(\%)\end{array}$} & \multicolumn{2}{|r|}{ Complications } \\
\hline & & & & & Rate $(\%)$ & Types \\
\hline $\begin{array}{l}\text { Lowe et al. } \\
(2007)^{29}\end{array}$ & 87 & $\begin{array}{l}\text { Endoscopic plus } \\
\text { fluoroscopic }\end{array}$ & $97(84 / 87)$ & $87(76 / 87)$ & $10(9 / 87)$ & $\begin{array}{l}\text { Tumor ingrowth/overgrowth }(\mathrm{n}=7) \\
\text { Stent migration }(\mathrm{n}=1) \\
\text { Perforation }(\mathrm{n}=1)\end{array}$ \\
\hline $\begin{array}{l}\text { Kim et al. } \\
(2007)^{6}\end{array}$ & 213 & Fluoroscopic & $94(201 / 213)$ & $94(196 / 209)$ & $21(45 / 213)$ & $\begin{array}{l}\text { Tumor overgrowth }(n=14) \\
\text { Stent collapse }(n=9) \\
\text { Stent migration }(n=8) \\
\text { Food impaction }(n=5) \\
\text { Jaundice }(n=5) \\
\text { Granulation tissue }(n=2) \\
\text { Bleeding }(n=2)\end{array}$ \\
\hline $\begin{array}{l}\text { van Hooft et al. } \\
(2009)^{1}\end{array}$ & 51 & $\begin{array}{l}\text { Endoscopic plus } \\
\text { fluoroscopic }\end{array}$ & $98(50 / 51)$ & $84(43 / 51)$ & $27(14 / 51)$ & $\begin{array}{l}\text { Tumor ingrowth }(n=5) \\
\text { Tumor overgrowth }(n=1) \\
\text { Stent migration }(n=1) \\
\text { Cholangitis }(n=3) \\
\text { Bleeding }(n=2) \text {, pain }(n=2)\end{array}$ \\
\hline $\begin{array}{l}\text { Bessoud et al. } \\
(2005)^{7}\end{array}$ & 72 & Fluoroscopic & $97(70 / 72)$ & $90(65 / 72)$ & $25(18 / 72)$ & $\begin{array}{l}\text { Tumor overgrowth }(n=5) \\
\text { Tumor ingrowth }(n=2) \\
\text { Stent migration }(n=8) \\
\text { Stent fracture }(n=1) \\
\text { Perforation }(n=1) \\
\text { Death related to general anesthesia } \\
(n=1)\end{array}$ \\
\hline $\begin{array}{l}\text { Telford et al. } \\
(2004)^{30}\end{array}$ & 176 & $\begin{array}{l}\text { Endoscopic plus } \\
\text { fluoroscopic }\end{array}$ & $98(173 / 176)$ & $84(133 / 159)$ & $9(14 / 159)$ & $\begin{array}{l}\text { Stent migration }(n=9) \\
\text { Perforation }(n=2) \\
\text { Bleeding }(n=2) \text {, pain }(n=1)\end{array}$ \\
\hline
\end{tabular}

the stent delivery system in the distended stomach but also because of the curved configuration of the duodenal C-loop. ${ }^{6,31}$ Due to the anatomic difficulties after surgery, a stricture in an anastomotic site (especially at the gastrojejunostomy site) is most challenging for stent placement. ${ }^{6,32}$ After stent placement, some patients may not show improvements in symptoms due to unrecognized distal small bowel strictures, ${ }^{6,7,12}$ lack of propulsive peristalsis in a chronically obstructed stomach, ${ }^{7}$ or functional gastric outlet obstruction due to neural involvement of the tumor. ${ }^{33}$

\section{STENT PATENCY}

Median stent patency has been reported to range from 146 to 385 days, ${ }^{1,2,6,9,20,32}$ with metallic stents showing adequate resolution of the GOO in the majority of patients until death. ${ }^{1,2,6,9}$ Median stent patency has been reported similar in patients with gastric carcinoma (350 days) and pancreatic carcinoma (385 days). ${ }^{2}$ Tumor ingrowth/overgrowth and stent migration have been regarded as the main causes of loss of patency of uncovered or covered stents. ${ }^{2,6}$ Chemotherapy after stent placement, which reduces tumor burden, thus decreasing the likelihood of tu- mor ingrowth and overgrowth, has been associated with an increase in duration of stent patency. ${ }^{6,30}$ In addition, chemotherapy may prevent or delay disease progression, thus prolonging patient survival. ${ }^{6}$

\section{COMPLICATIONS}

\section{Stent obstruction}

Obstruction is the most common complication ${ }^{1,6,28}$ $(12-17 \%)$ observed after stent placement and may be caused by food material, tumor ingrowth or overgrowth (Fig. 1), or stent collapse. Impacted food may be successfully removed endoscopically, ${ }^{6}$ whereas tumor ingrowth or overgrowth or stent collapse can be successfully treated by coaxial placement of another stent (Fig. 1). ${ }^{27,34}$

\section{Stent migration}

Migration rate is higher for covered $(21-26 \%)^{16,35}$ than for uncovered $(0-11 \%)$ stents. ${ }^{21,36,37}$ Stent migration is related to chemotherapy after stent placement (Fig. 2), but not to balloon dilation before or after stent placement. ${ }^{6}$ Stent migration can be managed by insertion of another stent. ${ }^{6,27,28}$ The migrated stent may pass out through the rectum or may be caught in the intestine and lead to ob- 

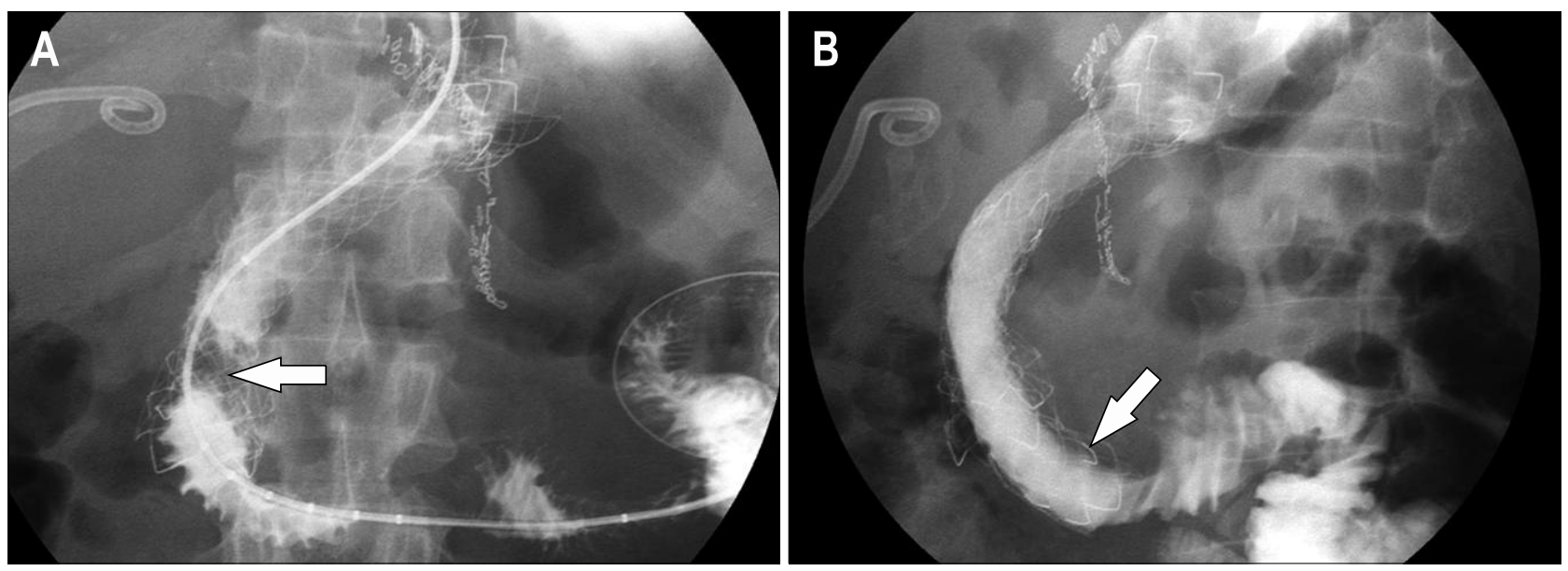

Fig. 1. A 48-year-old man with recurrent obstruction caused by distal tumor overgrowth. (A) Radiograph taken 2 months after stent placement showing tumor overgrowth (arrow) in the distal area of the stent. (B) Management of this complication by placement of a second stent (arrow) that overlapped the initial stent.
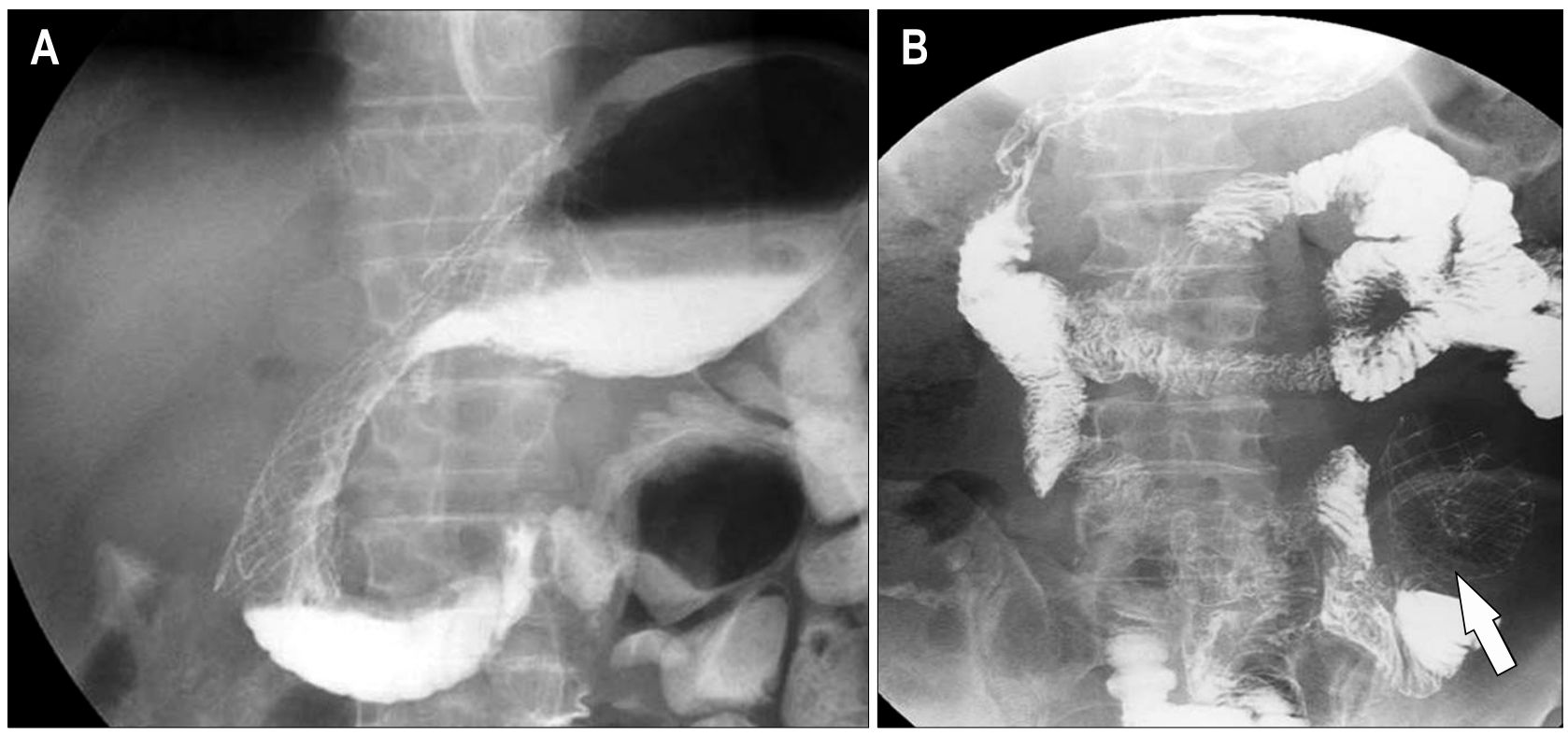

Fig. 2. A 57-year-old man with complete downward stent migration. (A) Radiograph taken immediately after stent placement showing the correct placement of the stent. (B) Radiograph taken 24 days after stent placement, showing complete downward stent migration (arrow). This patient had received chemotherapy after stent placement.

struction, requiring surgery. ${ }^{6,27,28}$

\section{Biliary obstruction}

The rate of biliary obstruction after gastroduodenal stent placement has been found to range from $1.3 \%$ to $6 \%$ (Fig. 3). ${ }^{6,28,30}$ The relationship between stent placement bridging the ampulla of Vater and biliary obstruction is unclear. Some researchers have suggested that the risks of such a biliary obstruction may limit the use of covered stents in patients with duodenal obstruction, ${ }^{38}$ suggesting the use of uncovered stents or mandatory biliary decompression prior to placement of a covered stent in the second portion of the duodenum. ${ }^{35}$ In contrast, other researchers have found that the rate of biliary obstruction after covered stent placement was not as high as expected, since approximation of the covering membrane of the stent to the duodenal wall is not complete even when the stent is completely expanded, allowing bile to drain through the space between the covering membrane of the stent and the duodenal wall. ${ }^{12,31,39}$ 

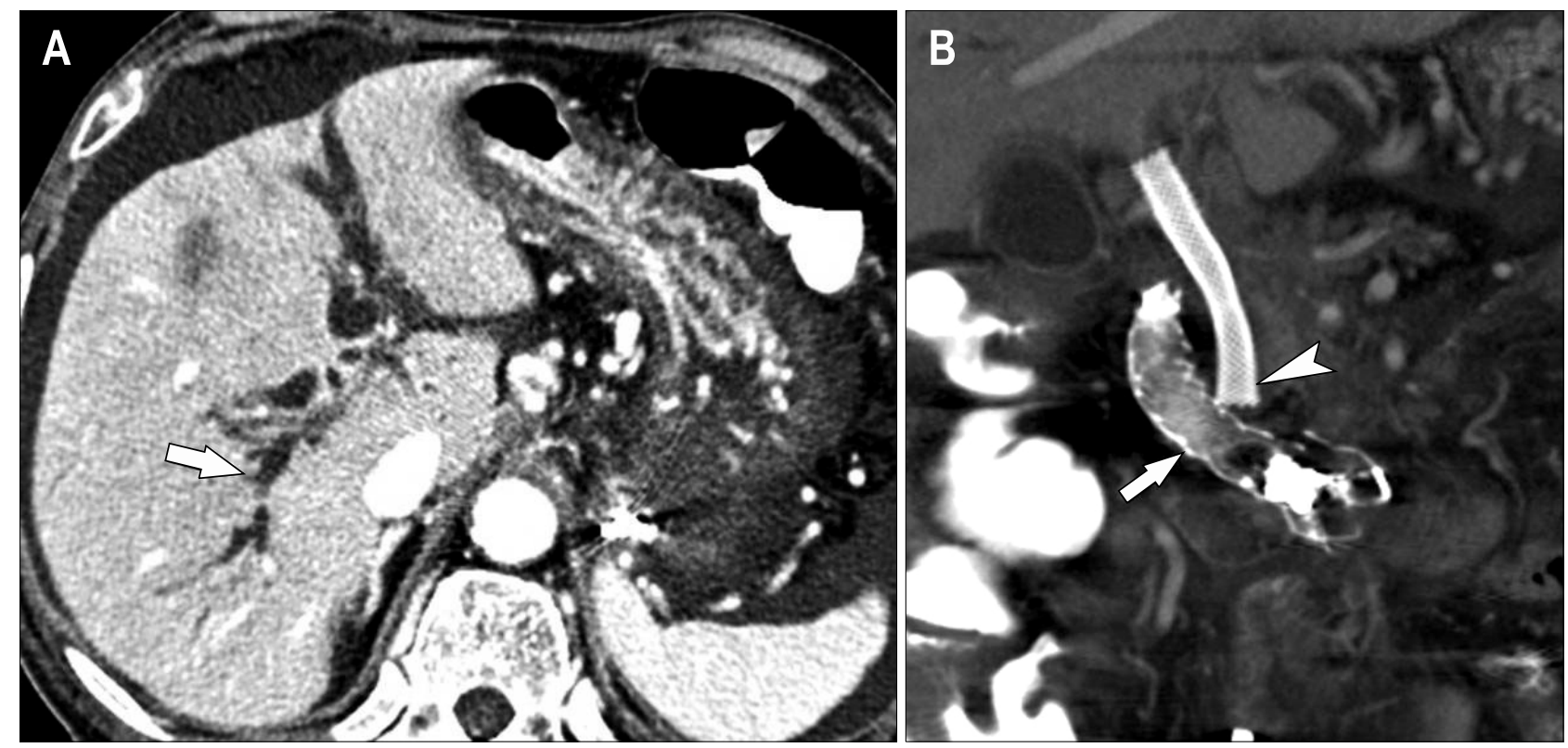

Fig. 3. A 77-year-old man with a biliary obstruction at 1 day after stent placement. (A) Axial computed-tomography image taken 1 day after stent placement showing bile-duct (arrow) dilatation. (B) Coronal computed-tomography image showing collision of the duodenal (arrow) and biliary (arrowhead) stents.

\section{Perforation}

Perforation is a life-threatening complication requiring urgent surgical treatment. However, perforation is very rare, occurring in fewer than $1 \%$ of patients. ${ }^{6,28}$ Perforation is usually caused by erosion of the bare ends of the stent through the wall of the intestine. Although not clear, there may be a relationship between perforation and radiation therapy after stenting for malignant GOO. ${ }^{40}$

\section{Bleeding}

Bleeding after stent placement is another rare complication, occurring in fewer than $1 \%$ of patients. ${ }^{6,28}$ Although bleeding can usually be managed by conservative treatment only, significant bleeding may require vascular embolization. $^{15}$

\section{Pain}

Abdominal pain lasts for 24-72 hours after stent placement and usually resolves spontaneously. ${ }^{19}$ Continuous pain can be treated with analgesics. $12,28,41$

\section{QUALITY OF LIFE}

Several studies using the Karnofsky scale have observed increases in Karnofsky scores after stent placement. ${ }^{42-45}$ The Karnofsky scale, however, captures only one aspect of quality of life (physical function) and is presently consid- ered inadequate for evaluation of overall quality of life. ${ }^{8}$ One randomized study using SF-36 Physical Health scores, a sensitive indicator of quality of life, ${ }^{46}$ found that these scores were significantly higher 1 month after stent placement than after laparoscopic bypass in the palliative treatment of malignant GOO. ${ }^{46}$ That study, however, included small numbers of patients (10 per group). Another study found that World Health Organization performance score improved, whereas global quality of life did not, after stent placement in 51 patients with malignant GOO. ${ }^{1}$ This discrepancy suggests that palliative treatment of patients with malignant GOO should not focus only on food passage but on other factors that may decrease quality of life, including pain, deterioration of physical condition, and mental support. ${ }^{1}$

\section{COVERED VERSUS BARE STENTS}

Since both covered and bare stents have advantages and disadvantages, it is unclear which is better in the palliative treatment of malignant GOO. Two recent studies compared the clinical outcomes of covered and bare stents in the palliative treatment of malignant GOO. ${ }^{40,47}$ A prospective, non-randomized study ${ }^{47}$ found that the technical and clinical success rates were similar in patients receiving covered $(n=70)$ and bare metal $(n=84)$ stents. Stent migration was significantly more frequent in the covered than in the bare stent group $(17.1 \%$ vs $0 \%$; $p$ 
$<0.001)$, whereas tumor ingrowth was more frequent in the bare than in the covered stent group $(16.6 \%$ vs $2.9 \%$; $\mathrm{p}=0.0066)$. Stent re-intervention rates and stent patency and patient survival periods were similar in these two groups. ${ }^{47}$ In the second study, retrospective in design, ${ }^{40}$ technical/clinical success rates, stent patency time, and patient survival period did not differ between the covered $(n=29)$ and bare $(n=32)$ stent groups. Moreover, the rate of complications (including reobstruction, migration, bleeding, and stent fracture) did not differ significantly between the two groups. Covered stents, however, were associated with a more frequent need for reintervention. ${ }^{40}$ Differences in study results may have been due to differences in patient demographics, stent type, and/or patient survival period. ${ }^{40,47}$ A large, prospective, randomized trial is required to find the ideal stent for patients with malignant GOO. ${ }^{40,47}$

\section{REFERENCES}

1. van Hooft JE, Uitdehaag MJ, Bruno MJ, et al. Efficacy and safety of the new WallFlex enteral stent in palliative treatment of malignant gastric outlet obstruction (DUOFLEX study): a prospective multicenter study. Gastrointest Endosc 2009;69:1059-1066.

2. Kim JH, Song HY, Shin JH, et al. Metallic stent placement in the palliative treatment of malignant gastric outlet obstructions: primary gastric carcinoma versus pancreatic carcinoma. AJR Am J Roentgenol 2009;193:241-247.

3. Piesman M, Kozarek RA, Brandabur JJ, et al. Improved oral intake after palliative duodenal stenting for malignant obstruction: a prospective multicenter clinical trial. Am J Gastroenterol 2009;104:2404-2411.

4. Maetani I, Isayama H, Mizumoto Y. Palliation in patients with malignant gastric outlet obstruction with a newly designed enteral stent: a multicenter study. Gastrointest Endosc 2007;66:355-360.

5. McLoughlin MT, Byrne MF. Endoscopic stenting: where are we now and where can we go? World J Gastroenterol 2008; 14:3798-3803.

6. Kim JH, Song HY, Shin JH, et al. Metallic stent placement in the palliative treatment of malignant gastroduodenal obstructions: prospective evaluation of results and factors influencing outcome in 213 patients. Gastrointest Endosc 2007;66:256-264

7. Bessoud B, de Baere T, Denys A, et al. Malignant gastroduodenal obstruction: palliation with self-expanding metallic stents. J Vasc Interv Radiol 2005;16:247-253.

8. Larssen L, Medhus AW, Hauge T. Treatment of malignant gastric outlet obstruction with stents: an evaluation of the reported variables for clinical outcome. BMC Gastroenterol 2009;9:45.

9. Gutzeit A, Binkert CA, Schoch E, Sautter T, Jost R, Zollikofer CL. Malignant gastroduodenal obstruction: treatment with self-expanding uncovered wallstent. Cardiovasc Intervent Radiol 2009;32:97-105.

10. Seo EH, Jung MK, Park MJ, et al. Covered expandable niti- nol stents for malignant gastroduodenal obstructions. J Gastroenterol Hepatol 2008;23:1056-1062.

11. Gaidos JK, Draganov PV. Treatment of malignant gastric outlet obstruction with endoscopically placed self-expandable metal stents. World J Gastroenterol 2009;15: 4365-4371.

12. Song HY, Shin JH, Yoon CJ, et al. A dual expandable nitinol stent: experience in 102 patients with malignant gastroduodenal strictures. J Vasc Interv Radiol 2004;15:14431449.

13. Del Piano M, Ballare M, Montino F, et al. Endoscopy or surgery for malignant GI outlet obstruction? Gastrointest Endosc 2005;61:421-426.

14. Hosono S, Ohtani H, Arimoto Y, Kanamiya Y. Endoscopic stenting versus surgical gastroenterostomy for palliation of malignant gastroduodenal obstruction: a meta-analysis. J Gastroenterol 2007;42:283-290.

15. Lopera JE, Alvarez O, Castano R, Castaneda-Zuniga W. Initial experience with Song's covered duodenal stent in the treatment of malignant gastroduodenal obstruction. J Vasc Interv Radiol 2001;12:1297-1303.

16. Park KB, Do YS, Kang WK, et al. Malignant obstruction of gastric outlet and duodenum: palliation with flexible covered metallic stents. Radiology 2001;219:679-683.

17. Kim JH, Song HY, Park SW, et al. Early symptomatic strictures after gastric surgery: palliation with balloon dilation and stent placement. J Vasc Interv Radiol 2008;19:565-570.

18. Song GA, Kang DH, Kim TO, et al. Endoscopic stenting in patients with recurrent malignant obstruction after gastric surgery: uncovered versus simultaneously deployed uncovered and covered (double) self-expandable metal stents. Gastrointest Endosc 2007;65:782-787.

19. Moon JH, Choi HJ, Ko BM, et al. Combined endoscopic stent-in-stent placement for malignant biliary and duodenal obstruction by using a new duodenal metal stent (with videos). Gastrointest Endosc 2009;70:772-777.

20. Jung GS, Song HY, Seo TS, et al. Malignant gastric outlet obstructions: treatment by means of coaxial placement of uncovered and covered expandable nitinol stents. J Vasc Interv Radiol 2002;13:275-283.

21. Song HY, Yang DH, Kuh JH, Choi KC. Obstructing cancer of the gastric antrum: palliative treatment with covered metallic stents. Radiology 1993;187:357-358.

22. Kim JH, Song HY, Shin JH, Jung HY, Kim SB, Park SI. Membrane degradation of covered stents in the upper gastrointestinal tract: frequency and clinical significance. J Vasc Interv Radiol 2008;19:220-224.

23. Zollikofer CL, Jost R, Schoch E, Decurtins M. Gastroduodenal and colonic stents: review article. Semin Intervent Radiol 2001;18:265-280.

24. Lindsay JO, Andreyev HJ, Vlavianos P, Westaby D. Self-expanding metal stents for the palliation of malignant gastroduodenal obstruction in patients unsuitable for surgical bypass. Aliment Pharmacol Ther 2004;19:901-905.

25. Bae JI, Shin JH, Song HY, et al. Use of guiding sheaths in peroral fluoroscopic gastroduodenal stent placement. Eur Radiol 2005;15:2354-2358.

26. Morgan R, Adam A. Use of metallic stents and balloons in the esophagus and gastrointestinal tract. J Vasc Interv Radiol 2001;12:283-297.

27. Sabharwal T, Irani FG, Adam A. Quality assurance guide- 
lines for placement of gastroduodenal stents. Cardiovasc Intervent Radiol 2007;30:1-5.

28. Dormann A, Meisner S, Verin N, Wenk Lang A. Self-expanding metal stents for gastroduodenal malignancies: systematic review of their clinical effectiveness. Endoscopy 2004;36:543-550.

29. Lowe AS, Beckett CG, Jowett S, et al. Self-expandable metal stent placement for the palliation of malignant gastroduodenal obstruction: experience in a large, single, UK centre. Clin Radiol 2007;62:738-744.

30. Telford JJ, Carr-Locke DL, Baron TH, et al. Palliation of patients with malignant gastric outlet obstruction with the enteral Wallstent: outcomes from a multicenter study. Gastrointest Endosc 2004;60:916-920.

31. Yoon CJ, Song HY, Shin JH, et al. Malignant duodenal obstructions: palliative treatment using self-expandable nitinol stents. J Vasc Interv Radiol 2006;17:319-326.

32. Song HY, Kim TH, Choi EK, et al. Metallic stent placement in patients with recurrent cancer after gastrojejunostomy. J Vasc Interv Radiol 2007;18:1538-1546.

33. Baron TH, Harewood GC. Enteral self-expandable stents. Gastrointest Endosc 2003;58:421-433.

34. Kim JH, Song HY, Shin JH, et al. Stent collapse as a delayed complication of placement of a covered gastroduodenal stent. AJR Am J Roentgenol 2007;188:14951499.

35. Jung GS, Song HY, Kang SG, et al. Malignant gastroduodenal obstructions: treatment by means of a covered expandable metallic stent-initial experience. Radiology 2000;216:758-763.

36. Binkert CA, Jost R, Steiner A, Zollikofer CL. Benign and malignant stenoses of the stomach and duodenum: treatment with self-expanding metallic endoprostheses. Radiology 1996;199:335-338.

37. Feretis C, Benakis P, Dimopoulos C, et al. Palliation of malignant gastric outlet obstruction with self-expanding metal stents. Endoscopy 1996;28:225-228.
38. Yates MR 3rd, Morgan DE, Baron TH. Palliation of malignant gastric and small intestinal strictures with self-expandable metal stents. Endoscopy 1998;30:266-272.

39. Kim SY, Song HY, Kim JH, et al. Bridging across the ampulla of Vater with covered self-expanding metallic stents: is it contraindicated when treating malignant gastroduodenal obstruction? J Vasc Interv Radiol 2008;19:1607-1613.

40. Maetani I, Ukita T, Tada T, Shigoka H, Omuta S, Endo T. Metallic stents for gastric outlet obstruction: reintervention rate is lower with uncovered versus covered stents, despite similar outcomes. Gastrointest Endosc 2009;69:806-812.

41. Tang T, Allison M, Dunkley I, Roberts P, Dickinson R. Enteral stenting in 21 patients with malignant gastroduodenal obstruction. J R Soc Med 2003;96:494-496.

42. Maetani I, Tada T, Ukita T, Inoue H, Sakai Y, Nagao J. Comparison of duodenal stent placement with surgical gastrojejunostomy for palliation in patients with duodenal obstructions caused by pancreaticobiliary malignancies. Endoscopy 2004;36:73-78.

43. Soetikno RM, Carr-Locke DL. Expandable metal stents for gastric-outlet, duodenal, and small intestinal obstruction. Gastrointest Endosc Clin N Am 1999;9:447-458.

44. Bethge N, Breitkreutz C, Vakil N. Metal stents for the palliation of inoperable upper gastrointestinal stenoses. Am J Gastroenterol 1998;93:643-645.

45. Schiefke I, Zabel-Langhennig A, Wiedmann $M$, et al. Self-expandable metallic stents for malignant duodenal obstruction caused by biliary tract cancer. Gastrointest Endosc 2003;58:213-219.

46. Mehta S, Hindmarsh A, Cheong E, et al. Prospective randomized trial of laparoscopic gastrojejunostomy versus duodenal stenting for malignant gastric outflow obstruction. Surg Endosc 2006;20:239-242.

47. Lee KM, Choi SJ, Shin SJ, et al. Palliative treatment of malignant gastroduodenal obstruction with metallic stent: prospective comparison of covered and uncovered stents. Scand J Gastroenterol 2009;44:846-852. 